\title{
The concept of an early warning system for the use of nuclear technology in Indonesia
}

\author{
Dewi Prima Meiliasari ${ }^{*}$, Berton Suar Panjaitan ${ }^{2}$, Toto Heryanto ${ }^{3}$, and Wilopo ${ }^{1}$ \\ ${ }^{1}$ Disaster Management Study Program, National Security Faculty, Republic of Indonesia Defense University, Indonesia \\ ${ }^{2}$ The Disaster Management Training Center, National Disaster Management Agency, Indonesia \\ ${ }^{3}$ Directorate of Technical Support and Nuclear Emergency Preparedness, Nuclear Energy Regulatory Agency, Indonesia
}

\begin{abstract}
The application of nuclear power plants in the world is increasing and has the potential for accidents, including nuclear weapons tests from outside the Nuclear Non-Proliferation Treaty, thus allowing radioactive releases to fall into Indonesian territory, which is a potential threat. Indonesia also utilizes nuclear power in many fields, thus also potentially becoming a national threat. To prevent the threat of radiation potential requires a nuclear disaster Early Warning System (EWS) that can be accessed by the community. This research analysed the EWS that Indonesia needed, using qualitative methods by describing the results of research obtained from interviews and secondary data. Results and research discussions starting from observation and monitoring of radiation exposure, warning services, information dissemination, and supported by countermeasures for the effectiveness of the EWS. The results showed that the development of an integrated nuclear disaster EWS that is easily accessible to the community quickly and continuously under the development of an emergency is a strategy as a decision to reduce the risk of nuclear disaster. The development of the strategy requires a legal basis that regulates coordination between ministries/institutions, from planning to information dissemination to ensure the safety of the public and Indonesian people's security.
\end{abstract}

\section{Introduction}

The use of nuclear power has been known since World War II as a weapon to destroy the cities of Hiroshima and Nagasaki in 1945, until now nuclear power is used by the world. According to data released by the World Nuclear Association in 2007 on the Indonesian National Nuclear Agency website, there were 436 uses of nuclear power used for Nuclear Power Plants (NPP) which operate in 33 countries around the world and can generate electricity as much as $16 \%$ of the world's electricity needs. Based on data from the International Atomic Energy Agency (IAEA) in 2018, the United States is the largest country operating nuclear power plants in the world with 99 units, followed by France in second place with the number of nuclear power plants reaching 58 units. The use of nuclear power as nuclear power plants worldwide is dominated by European countries, the United States, and several developed countries in Asia such as China, Japan, India, and South Korea, as well as 15 other countries that have just built nuclear power plants $[1,2]$.

The operation of nuclear power plants around the world is not only beneficial but also has the potential for radioactive release to the environment, both under normal operating conditions and in accidental conditions that cause exposure to the public and the environment.

In the event of an accident, the release of fission product in large quantities with long half-lives, through the atmosphere through world global winds which have an altitude above $800 \mathrm{~m}$ will be very likely to be carried up to enter the Indonesian atmosphere and with high rainfall conditions, the slowing down wind speed at the time of the wind direction deflection and the high surface altitude will very likely allow the fission product radionuclides to fall into the surface of the region in Indonesia. Indonesia's geographical position, which is located between countries operating nuclear power plants around the world, has the potential to be exposed to radioactive release in the event of an accident so that it becomes a potential global threat given in Figure 1 .

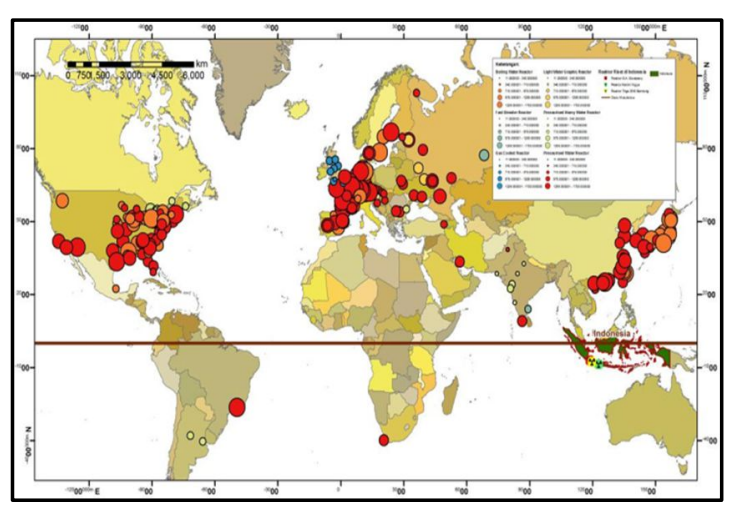

Fig. 1. The potential global radiation threat.

Indonesia as a country that ratified the Nuclear NonProliferation Treaty (NPT) has utilized nuclear technology in various fields, i.e health, industry,

* Corresponding author: d.meiliasari@bapeten.go.id 
agriculture, and research. In the fields of 1 . Health, it is used as a radiodiagnostic and interventional tool, radiotherapy, and nuclear medicine; 2 . Industry, as a tool for material analysis ( $X R F$, logging), food preservation, sterilization of medical devices, non-destructive testing (radiography), measurement (gauging), Tracer, and Imaging (checking baggage or containers); 3. Agriculture, for breeding rice seeds to produce superior rice varieties, to preserve ready-to-eat food, slowing down shoots in tubers, preserving fruits; and 4. Research carried out to support the development of the nuclear industry and preparation for the construction and operation of nuclear power plants in Indonesia carried out at the Triga 2000 (2 MW) reactor in Bandung, the Kartini Reactor $(250 \mathrm{~kW})$ in Yogyakarta, and the Siwabessy Multipurpose ReactorGA ( $30 \mathrm{MW}$ ) in Serpong. In addition to being useful, the use of nuclear technology also has a great potential for the release of radioactive substances in the event of an accident. The location of the use of nuclear power in Indonesia as a potential threat is given in Figure 2.

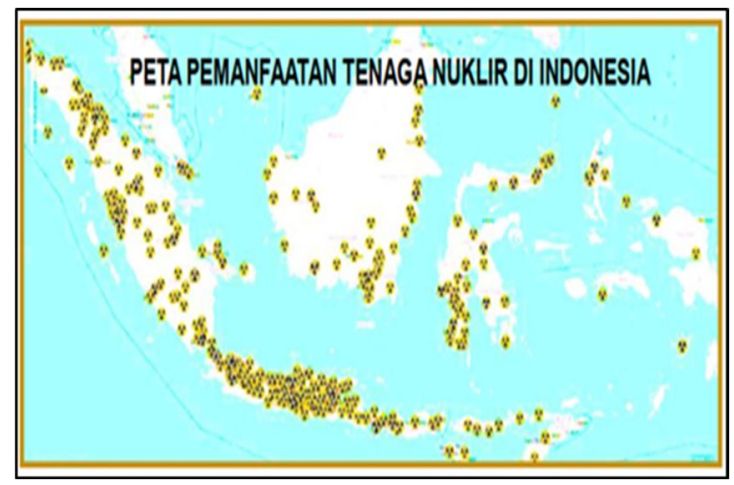

Fig. 2. The potential national threat.

The use and distribution of nuclear power plants and radioactive substances (ZRA) globally and nationally is a global, regional and national security threat, and the use of nuclear power for weapons testing increases the potential danger of radioactive release or contamination caused by nuclear emergencies from within or outside the territory of the Republic of Indonesia.

Nuclear weapons tests have been detected by several stations of the Meteorology, Climatology and Geophysics Agency (BMKG) on January 6, 2016, at 08.30.01 WIB, an unusual vibration on the earth's surface has been detected near the location of North Korea's nuclear test facility as reported on the website. BMKG official. The detection of vibrations caught by BMKG only identifies the location of the vibrations but has not been able to identify the possibility of radioactive fallout that may occur in the territory of Indonesia. The existence of equipment capable of detecting a fallout in Indonesia that is capable of functioning as a nuclear early-warning system is deemed necessary to be paired with the equipment already owned by BMKG to ensure the creation of protection and a sense of security for all Indonesian people.

An EWS for radioactive releases into the Indonesian environment is an effective nuclear emergency response monitoring system capable of monitoring the latest radiation levels in real-time, which is needed in several locations as an EWS, to enable the public to respond appropriately as a rescue and to avoid casualties, and to reduce the risk of disasters due to exposure to radioactive releases.

The Fukushima disaster in Japan that occurred in March 2011 taught a lesson that it is not enough just to have the equipment to detect radioactive releases with advanced technology, but also an EWS that can disseminate information quickly to the public in the early stages of an emergency, to communicate and coordinate, and to quickly report the status of an emergency to the IAEA [3]. Communication and coordination between authorized institutions that observe disaster symptoms and the National Disaster Management Agency (BNPB) and/or Regional Disaster Management Agency (BPBD) according to the location of the disaster level, as a basis for making decisions on disseminating information to the government, private broadcasters, and mass media for resource mobilization, so that the public can prepare themselves as an effort to reduce the risk of radioactive releases into the environment.

\section{Methods and Data}

The method in this study uses a qualitative method intending to get a detailed description of the EWS starting from observing the symptoms of radioactive release into the Indonesian environment so that the public can make efforts to reduce the risk of radioactive release. Data in the field were obtained through interviews and supported by secondary data collected by researchers. The research results are described qualitatively based on existing theories.

\section{Theory}

Early warning in Law Number 24 of 1997 concerning Disaster Management is a series of activities as an early warning received by the community that a disaster will occur. Early warning is a combination of technological capabilities and the ability of policymakers, as well as the ability of the community to follow up as an effort to reduce the risk of radioactive releases into the Indonesian environment. Early warning as part of disaster risk reduction begins with observing existing disaster symptoms, analysing the results of observing disaster symptoms, making decisions by the authorities, disseminating disaster warning information, and taking action by the community. Community action on radioactive releases into the environment is carried out immediately after an early warning is given following the amount of contamination in the environment. The community performs temporary protection at home (sheltering), evacuates, and takes iodine tablets [4]. If one of these components is not met, the EWS will not be successful as a whole.

The EWS is a specific link (critical link) between preparedness actions and emergency response activities. There are 2 (two) factors that play a role in the framework of the EWS, namely the Decision Makers and the Community. On the community side, there are 3 (three) elements that determine how the community reacts to the EWS. These elements consist of Knowledge, Attitude, and Skill. The first step in shaping the community's 
reaction to the EWS is to provide information about the EWS. For people who have obtained this information knowledge, it is hoped that there will be a positive attitude change towards the EWS. This change is expected to be able to make people behave positively towards the EWS. If the stages of change in the community's reaction to the EWS are as expected, the EWS can reach the community accurately [5].

In addition to community factors, other factors that play a role in the framework of the EWS are the decisionmakers. In Indonesia, through the Government Regulation of the Republic of Indonesia Number 21 of 2008 concerning the Implementation of Disaster Management, the results of the analysis of observations of disaster symptoms from the EWS are submitted to BNPB and BPBD [6]. As we all know that disaster management and handling of refugees are coordinated by BNPB at the national level, regional management by BPBD. Through the existence of this institution, policies related to the EWS can be made, especially those related to the framework of the EWS, such as fixed procedure, Guidelines, and Work Mechanisms. Thus the EWS as an initial sub-segment in the preparedness stage can play a good role so that in the end when a disaster occurs, its severity can be controlled. With a good conceptual framework, the EWS as a link between preparedness actions and emergency response activities will result in response activities that lead to disaster management so that disaster victims can be reduced.

\section{Observation of Disaster Symptoms}

Risks can occur because of the threat of disaster risk (hazards), vulnerabilities, and levels of capacity [7]. The threat has been identified by researchers in preliminary research as described above, that the threat of radioactive release risk can come from global threats due to the use of nuclear power in the world as nuclear power plants and nuclear tests, as well as national threats from nuclear use in the fields of health, agriculture, industry, research in Indonesia [8].

The rapid increase in the population of Indonesia, increasing of housing land, offices and other public services office and approaching the area of nuclear technology utilization. Public education factors are still low, including disaster science, especially nuclear disaster risk reduction measures, and the lack of awareness of local governments in nuclear hazard risk preparedness [9]. This vulnerability is a threat to the risk of radiation exposure to the Indonesian environment.

Capacity building can be achieved by developing a nuclear disaster EWS in Indonesia. In developing a nuclear disaster EWS, it is based on Article 67 of Government Regulation Number 54 of 2012 concerning Safety and Security of Nuclear Installations which stipulates that early warning equipment is an element of infrastructure in the nuclear preparedness program, and in Article 16 of the Regulation of the Chairman of the Nuclear Energy Regulatory Agency Number 1 of 2010 concerning Nuclear Emergency Preparedness and Response, which regulates the authority of the licensee (PI) to develop an early detection system for nuclear emergencies, but has not regulated the authority of the nuclear energy regulatory agency (BAPETEN) in developing an EWS as a system that ensures the safety and security of the public from nuclear disasters [10-13].

In the Presidential Instruction of Indonesia, Number 4 of 2019 concerning Capacity Building in Preventing, Detecting, and Responding to Disease Outbreaks, Global Pandemics, and Nuclear, Biological, and Chemical Emergencies, the President of the Republic of Indonesia gave instructions to the Chairman of the Nuclear Energy Regulatory Agency to increase the ability to detect and respond to the occurrence of nuclear emergencies, whether arising from nuclear accidents in the use of nuclear energy for peaceful purposes, or all forms of use of nuclear energy for non-peaceful purposes, such as the misuse of nuclear materials or radiation sources by North Korea in nuclear weapon tests, and other activities. such as sabotage, and theft $[3,14]$.

The nature of presidential instructions according to Jimly [15], only as "policy rules" that is a form of policy regulation that cannot be categorized as a form of legislation, formally it cannot be called an official regulation, because it is only limited to providing direction in terms of carrying out tasks. Seeing the importance of an EWS in anticipation of a nuclear disaster and as a mitigation effort to reduce the risk of nuclear threats. Therefore, it is necessary to have laws and regulations related to the EWS as a legal basis in the implementation of monitoring the detection and response of radioactive releases, which include regulations regarding the responsibilities and authorities of ministries, institutions, and local governments related to the nuclear disaster EWS, and governance how to implement an EWS.

The existence of laws and regulations regarding the nuclear disaster EWS can be the basis for making policies in developing an EWS, so that efforts to strengthen and develop a sustainable nuclear disaster EWS are created and synergize between institutions to improve the safety of life and property of the Indonesian people.

\section{Monitoring and Warning Service}

\subsection{Analysis of Observational Data}

To defend the Unitary State of the Republic of Indonesia (NKRI), Indonesia builds, develops, and operates a national EWS as integrated and efficient monitoring and supervision of radioactive releases to the environment in the territory of the Republic of Indonesia. Radioactive release EWS becomes real-time data that can be accessed online for monitoring radioactivity to the environment of the Republic of Indonesia.

Online data which in its planning can be accessed by all parties and the community based on social networks, has been able to be integrated with the International Radiation Monitoring Information System (IRMIS) owned by the IAEA. So that if an environmental radioactive release is detected into the territory of the Republic of Indonesia, the public can immediately take action to reduce the risk of a nuclear disaster, and the 
IAEA will be immediately informed and will take action in emergency communication.

One of the detection equipment for the nuclear disaster early warning information system has been installed in several locations of vital objects, including 1 . In the Serpong nuclear area, 6 detectors have been installed; 2 . In the Bandung nuclear area, 1 detector has been installed; 3 . In the Yogyakarta nuclear area, 1 detector has been installed; 4. In the palace of the independent state, 1 detector has been installed; 5. The BMKG CTBT station has been installed with 5 detectors; 6 . The BMKG station has installed 10 detectors depicted in Figure 3; and the location of other vital objects that are still in the planning.

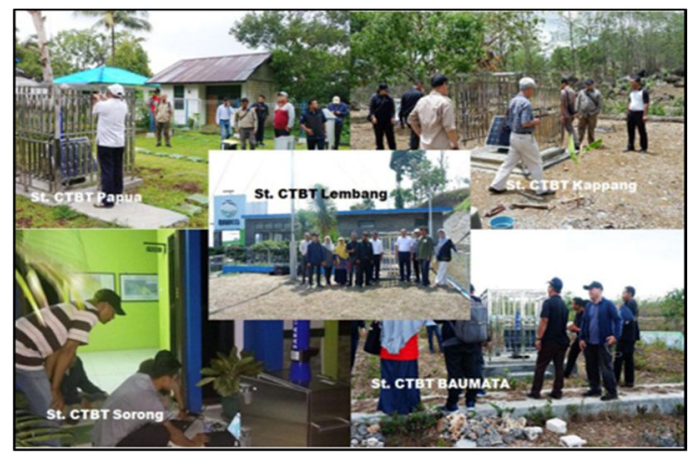

Fig. 3. Built-in IRDMS detector.

Radiation exposure is monitored in real-time that can be accessed online by the detector system supervisor officer every time. If there is an increase in radiation exposure in one region, the red alarm will appear at the BAPETEN - Nuclear Emergency Centre as shown in Fig. 4, it also displayed on the dashboard data on the NMC monitor web application given in Figure 5, the system will also notify the office by email and Short Message Service (SMS) and real-time data is monitored in the NMC Web application on Figure 6.

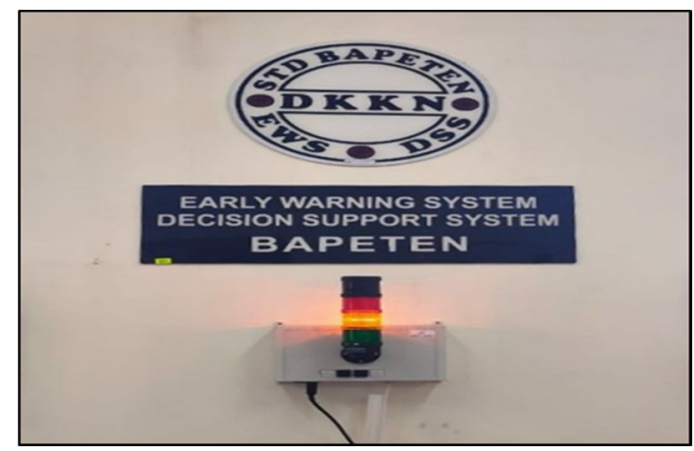

Fig. 4. EWS Alarm.

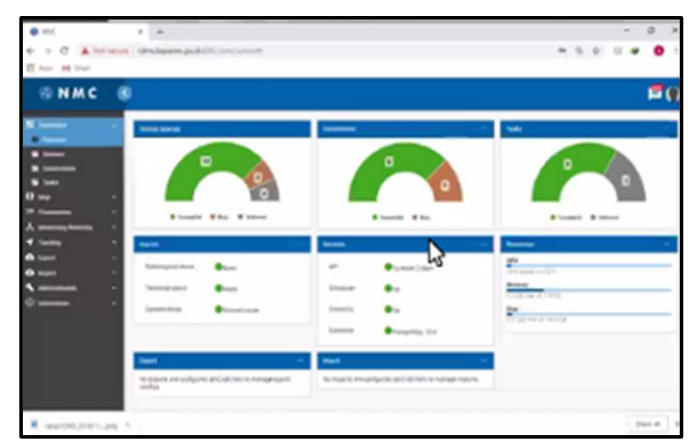

Fig. 5. Dashboard data.

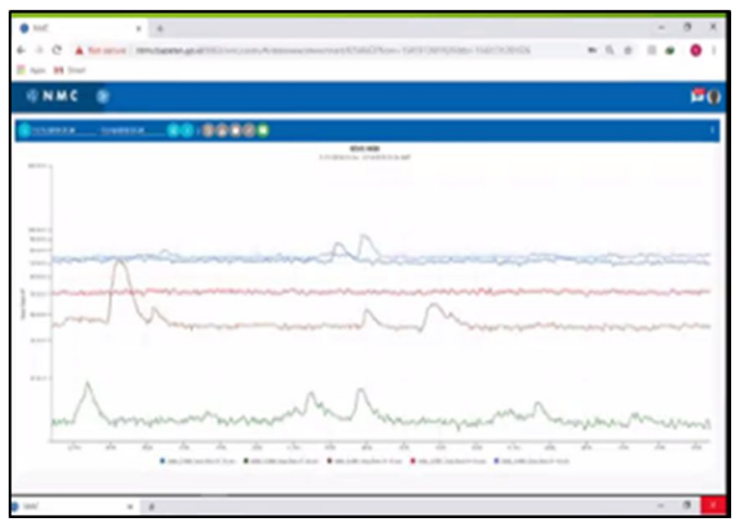

Fig. 6. $\mathrm{NMC}$ web app.

Figure 6 illustrates that there is an increase in radiation release which can be seen from the image of a wave that curves higher than the others, but the increase in radiation release in Figure 6 is still considered within normal limits because in abnormal conditions it appears in yellow or red.

\subsection{Decision-Based on the Analysis Result}

Nationally, the nuclear emergency management system is part of the National Disaster Management System. At the national level, this arrangement is coordinated by the National Disaster Management Agency. Currently, all Ministries and other institutions have been trying to build an integrated EWS at the national level, so that all efforts and capabilities in the field of disaster management can be implemented synergistically.

A synergistic radioactive release EWS is also part of the plan in the development of integration with the application of radiological impact analysis and geospatial information systems (GIS) named the National EWS (NEWS). It is going to be a data integration system between the Central Statistics Agency (BPS), the National Institute of Aeronautics and Space (LAPAN), and BMKG. N-EWS detector as confirmatory data and also assessment for predictions of radiological failure. N-EWS can confirm the correctness of the prediction results if there is information from the licensee about an accident that results in a radioactive release, the N-EWS detector application can confirm the analysis of radiological impacts in certain areas with a certain distance from the analysis data based on the geospatial information system. Data that has been integrated into information on EWS for BNPB, BMKG, IRMIS, Association of Southeast Asian Nations Network of Regulatory Bodies on Atomic Energy (ASEANTOM). An integrated nuclear disaster EWS is given in Figure 7.

Currently, the implementation of the decision on the nuclear disaster EWS is based on the results of coordination between BAPETEN and the BMKG after analyzing the symptoms of a nuclear disaster from the early warning information systems that have been installed in various regions. The results of the decision on the occurrence of radioactive releases are submitted by the Chairman of BAPETEN to the Chairman of BNPB/Provincial BPBD/City BPBD following the mandate of Law Number 24 of 1994 and Government 
Regulation Number 54 of 2012 and information on early warning of radioactive releases has been integrated with the IRMIS-IAEA system so that all Nuclear accident events that result in the release of radiation into the Indonesian environment can be known by the IAEA $[5,13]$.

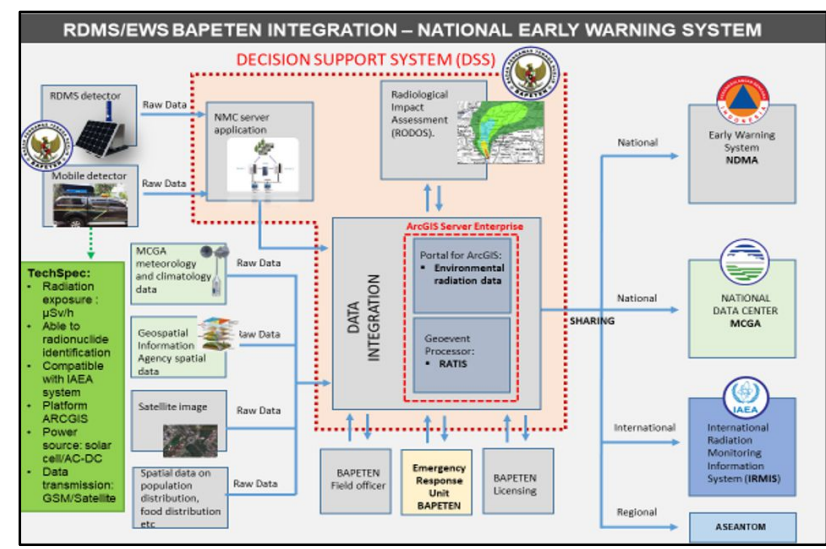

Fig. 7. Nuclear disaster EWS integration architecture.

BAPETEN together with BMKG has decided to verify an issue of nuclear radiation exposure in the South China Sea from online media on November 20, 2019, based on the early warning monitoring system of Radiological Data Monitoring Systems (RDMS) sensors which were installed side by side with the BMKG earthquake monitoring station network in Tarakan, Tanjung Pinang, and Gorontalo. From the results of RDMS no significant radiation level was detected compared to natural radiation levels, this symptom analysis is supported by the results of seismic recording analysis in two locations close to the estimated location of nuclear explosions in the South China Sea, namely in Vietnam and Taiwan that there is no seismic signal anomaly that shows a result of a nuclear explosion [9].

The results of the BAPETEN agreement with BMKG regarding the undetected nuclear disaster in the South China Sea can be accessed on social media, with the aim that all parties and the public can know and be able to reduce public concerns about the release of radiation hazards to the environment, especially people who live and earn income from the sea in the sea around the South China Sea.

\section{Information dissemination}

Dissemination of information to the public, mass media, and agencies related to the situation and condition of the facility-level nuclear emergency is carried out by the licensee based on the nuclear preparedness program of the facility that has been determined. The facility's nuclear preparedness program according to the IAEA (2015) in IAEA GSR Part 7 requirement 10 contains procedures for providing information, instructions, and warnings to the community around the facility or activity during an emergency [16]. Researchers still see that the facility's nuclear preparedness program has not been updated according to the latest references.

Nuclear emergency information to the public, mass media, and related agencies is sourced from information collection at the Control Command Center (PUSKODAL), information is provided by public relations at the facility. Dissemination of information to the public can also be carried out during nuclear emergency training and exercises, training is carried out once a year for facility-level nuclear emergencies, every two years for nuclear emergency training at the provincial level carried out by the provincial BPBD, and once every four years for training and exercises. Nuclear emergency at the national level organized by BNPB and involvement of the community around the reactor in nuclear emergency training and exercises need to be carried out to reduce the risk of nuclear disaster.

The Governor declares the status of a nuclear emergency at the provincial level to the public based on a recommendation from the Chairman of BAPETEN, in the event of a dose rate of $5 \mathrm{mSv} /$ hour or more measured for ten minutes or more at the installation site boundary and in the event of abnormal radioactive release with a concentration of air activity equal to or exceeding a dose rate of $5 \mathrm{mSv} /$ hour at the installation site limit detected from the normal release level, while for a nuclear emergency at the national level, a declaration of an emergency status is made by the President based on a recommendation from the Chairman of BAPETEN because the dose rate is $500 \mathrm{mSv} /$ hour or more which is measured for 10 minutes or more at the installation site boundary, and if abnormal radioactive release conditions with a concentration of air activity equal to or exceed a dose rate of $500 \mathrm{mSv} /$ hour at the installation site boundary detected from the normal release path.

\section{Countermeasures}

Nuclear disaster management capability is implemented according to GSR Part 7 from a series of capabilities that are prepared systematically and planned based on nuclear emergency management guidelines or procedures, starting from preparedness, nuclear emergency response until the nuclear emergency response is declared ended [2].

Quick, precise, effective, and efficient handling of nuclear emergencies is carried out by anticipating nuclear emergencies through the provision of infrastructure and the capability of the response function [13]. The infrastructure prepared for the response capacity includes: 1. the establishment of a nuclear disaster emergency management organization so that the responsibilities and authorities between parties are seen to be integrated into carrying out nuclear emergency management, which consists of a chairman and implementer (operations controller, operations operator, radiology reviewer, public relations and Chairman of ministries and related institutions); 2. Coordination between organizations is an important pillar in carrying out integrated nuclear emergency management so that it can run following the nuclear disaster emergency management plan that has been made so that nuclear disaster management plans must be made and updated according to current conditions; 3. Facilities and equipment prepared, including early warning and alarm equipment as a means of detecting the early release of radioactive sources, either 
in the form of online data or in the coordination system for reporting from the nuclear emergency response team; 4. Procedures and work instructions as guidelines for the technical implementation of nuclear disaster emergency management, including reporting procedures and coordination of decisions on early warning information systems; emergency response procedures for handling victim decontamination; procedures for providing information to the public; evacuation procedures for victims which include gathering points, temporary shelters, Mashall yards, triage rooms and so on; 5. Nuclear emergency training and exercise are carried out periodically according to the level of the nuclear disaster category.

The countermeasures functions in carrying out nuclear emergency response measures include 1 . Identification of nuclear disaster symptoms from the nuclear disaster EWS, reporting after disaster symptoms have occurred to BAPETEN as the institution that guarantees the safety and security of the use of nuclear energy, and activating notification systems and activating emergency management organizations. nuclear following procedures for dealing with nuclear emergencies; 2. Mitigation measures to reduce the escalation of radiological hazards, reduce the potential threat of radioactive release, and reduce the impact of the release of radioactive substances to the community; 3. Protection measures are taken immediately after the impact of the accident exceeds the intervention level by providing iodine tablets, sheltering, and evacuation immediately after getting the results of disaster symptoms from the nuclear disaster EWS; 4. Protection measures against nuclear emergencies for workers, the community, and the environment by providing iodine tablets, sheltering, evacuation, and using personal protective equipment for nuclear emergency response officers, monitoring dose acceptance, limiting dose acceptance, taking action against excess doses, and decontamination of personnel; and 5. continuous provision of information following the development of the emergency to the public in emergency response to a nuclear disaster is an important action so that the public immediately takes measures to protect themselves against the effects of radioactive releases, the instrument for disseminating information is also a concern so that the public can quickly receive the latest news on the actual situation by through print or electronic media.

\section{Conclusion}

It was concluded that EWS in real-time which was able to detect the threat of radioactive release that occurred in national and global in the prevention of nuclear disaster emergencies is needed so that people can receive information through print and electronic media quickly and continuously following the development of nuclear disaster emergencies.

The nuclear EWS integrated with the EWS owned by other ministries / Institutions is a strategy for the effectiveness of information on nuclear disaster early warning information systems. It needs coordination to produce an agreement according to the results of data analysis to achieve the effectiveness of information data. Coordination starts from planning to disseminating information continuously to the community.

EWS integrated with the detector system, able to coordinate systems with national and international and also related ministries/institutions, including $\mathrm{BMKG}$, BPS, LAPAN, BNPB, IAEA -IRMIS, ASEANTOM in data integration, so that the community can access the information system early nuclear emergency. It is required legislation as a legal basis in the development of an integrated nuclear disaster EWS, which regulates a comprehensive EWS including coordination between ministries/institutions related to planning to disseminate information continuously to the public to ensure the safety of the community so that Indonesia's security is created.

\section{References}

1. K. Kelleher, at Nucl. radiol. Emergency Anime. Whipped. Preparation System. Response Recovery. Springer, Berlin, Heidelberg, 35-52 (2021)

2. IAEA, Nuclear or Radiological Emergency Preparedness and Response. IAEA Safety Standard Series No. GSR Part 7 (International Atomic Energy Agency, Vienna (2015)

3. A. Dewi, Fukushima Accident for Improving the National Nuclear Preparedness Performance System, (Proceedings of the Nuclear Safety Seminar, 286-296 (2013)

4. T. Heryanto, Evacuation Analysis of People Affected by Radiation Hazards Due to Nuclear Accidents, Defense University, (2015)

5. A. Y. Pratiwi, The Role of the IAEA in the Development of Nuclear Power for Non-Peaceful Purposes, Calyptra 3 (2014)

6. RI, Law Number 24 Year 2007 on Disaster Management (Government of the Republic of Indonesia, Jakarta, 2007)

7. S. Maarif, Thoughts and Disaster Management in Indonesia (National Agency for Disaster Management, Jakarta, 2012)

8. RI, Law of the Republic of Indonesia No. 10 of 1997 concerning Nuclear Energy (Government of the Republic of Indonesia, Jakarta, 1997)

9. A. Dewi, BNPB Preparedness in Facing Nuclear Disaster Threats in Indonesia, Defense University, (2020)

10. BATAN, Research and Development Results of BATAN in the Energy Sector, (2019)

11. UTI, Batan and World Nuclear Association Hold World Nuclear Spotlight Seminar, (2018)

12. Bapeten, Regulation of the Head of the Nuclear Energy Supervisory Agency Number 1 of 2010 concerning Preparedness and Response to Nuclear Emergencies (Bapeten, Jakarta, 2010) 
13. RI, Government Regulation of the Republic of Indonesia No. 54 of 2012 concerning the Safety and Security of Nuclear Installations (Government of the Republic of Indonesia, Jakarta, n.d.)

14. RI, Presidential Instruction No. 4 of 2019 concerning Capacity Building in Preventing, Detecting, and Responding to Disease Outbreaks, Global Pandemics, and Nuclear, Biological, and Chemical
Emergencies (Government of the Republic of Indonesia, Jakarta, 2019)

15. J. Asshiddiqie, Regarding Laws in Indonesia (Raja Grafindo Persada, Jakarta, 2011)

16. D. Apriliani and I. D. K. K. Widana, Proposals for the Implementation of Nuclear Preparedness Programs in the Utilization of Radiation Facilities and Radioactive Substances, (Proceedings of Nuclear Safety, 2019), 371-379 (2019) 